\title{
Theoretical study on Cold Open Die Forging Process Optimization for Multipass Workability
}

\author{
Ajitkumar Gaikwad ${ }^{1-a}$, Shreyas Kirwai ${ }^{1}$, Provat Koley ${ }^{2}$, Dr. G. Balachandran ${ }^{3}$ and Dr. Rajkumar Singh $^{1}$ \\ ${ }^{1}$ Kalyani Centre for technology and innovation, Bharat Forge Ltd., Pune, India \\ ${ }^{2}$ Heavy Forge Division, Bharat Forge Ltd., Pune, India \\ ${ }^{3}$ Kalyni Carpenter Special Steels Itd., Pune, India
}

\begin{abstract}
Cold Workability limits strength enhancement of austenitic materials through cold deformation. The intrinsic workability is the material characteristic whereas state-of-stress workability is governed by nature of applied stress, strain rate and geometry of deformation zone. For Cold Open Die Forging (CODF), multipass workability is essential. In this work, FEM tool FORGE-3 is used to optimize CODF on hydraulic press by analysis of stress-strain profiles and use of Latham-Cockroft damage criterion. Study recommends optimized process parameters, die combinations and pass-schedules.
\end{abstract}

\section{Introduction}

The material properties of Austenitic Stainless Steels (ASS) are sensitive to plastic deformation. A significant improvement in the yield strength of ASS can be achieved by its cold deformation as a result of work/strain hardening. Austenitic stainless steels have a very high strain hardening coefficient and hence, can be effectively strain hardened to a very high strength.

This concept is used in some industrial applications where long bars of ASS are required to be cold forged to achieve certain strength levels. Having very high Length to Diameter $(\mathrm{L} / \mathrm{D})$ ratio, these are required to be processed through incremental or Open Die Forging route. Though, specialized machines/presses are developed for these kinds of processes, a thought was given to use general purpose open die forging hydraulic press with proper process design.

The amount of plastic deformation, and so the corresponding strength enhancement, without defect formation in deforming body, is limited by workability. In addition to intrinsic workability of the material, workability is also the characteristic of the metal working process followed.

In the present study, open die forging process with different process parameters and die combinations is analysed using FORGE-3. The objective of the study is to recommend, based on Finite Element Method (FEM) studies, an optimized process in order to get the desired degree of deformation without centre burst. Exact degree of deformation to achieve the desired enhancement in strength level can be decided only after actual shop floor trials. With this in mind, here, different process routes are analysed and compared on the basis of stress-strain profiles and Latham-Cockroft damage criterion.

Workability is the extent to which material can be shaped by plastic flow without onset of fracture. It is well understood that cold workability is not only influenced by microstructure of the material (ductility of the material), strain and the strain rate, but also by the stress state in the deformation zone [1]. Hence it is always convenient to consider workability to consist of two independent parts i.e. State of stress (SOS) workability and intrinsic workability. Intrinsic workability is governed by material properties like chemistry, microstructure, prior processing history and its response to the strain and strain rate at room temperature. The SOS workability depends on geometry of deformation zone in which workpiece is subjected to a three dimensional state of stress. The state of stress is represented by stress tensor with shear stress components and hydrostatic components. The shear stress components contribute to the plastic flow of the material while hydrostatic components decide the workability. The Hydrostatic components need to be essentially compressive as tensile components will open up the weak interfaces within deforming material causing the internal fracture. Hence, SOS workability is controlled by nature of applied stress and geometry of deformation zone and is specific to particular mechanical working process. One can play with this SOS workability by playing with die design and other process parameters in order to achieve the desired degree of plastic deformation.

In a typical open die forging, workpiece is hold at one end in manipulator, which is capable of rotating the job around its axis and also provides linear motion in axial direction. In this way manipulator positions the job between the dies and the press. The process is carried out

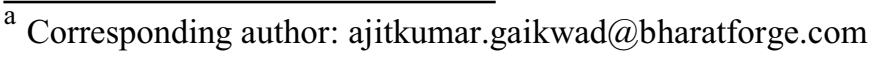


incrementally, with only a part of workpiece being deformed at a time. The tool i.e. die sizes are quite small than the overall size of the forging. Dies used are of simple shape like flat die, ' $V$ ' dies or simple contoured dies. As the only part of the workpiece is being deformed at a time, the requisite forging loads are less than those needed to deform entire workpiece at a time. The reduced forging load means lower capacity machine can be used to produce given part.

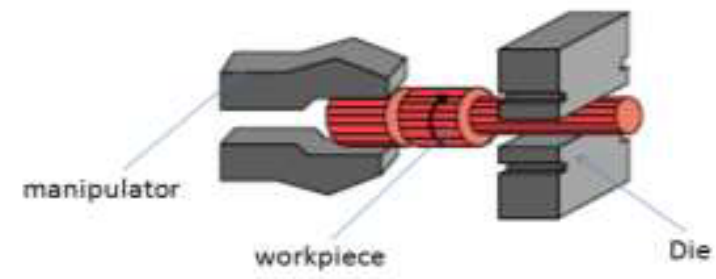

Fig. 1. Open die forging system

In open die forging, in addition to SOS workability, the ability of the metal to withstand the fracture or defect development in the face of progressive straining in multiple drawing/cogging passes is important criterion. This should be achieved without the benefit of intermediate annealing as annealing will again bring down the enhanced strength. Generally, this Multipass workability is tied to the resistance to ductile fracture. It is important to know that in some materials 'Multipass' workability may be so limited that fracture occurs at strains or reductions below those commonly undertaken in a single drawing pass (up to about $40 \%$ ). During such Multipass cogging operations, this ductile fracture generally occurs at centre of deforming body called as centerburst [2]. Figure 2 shows typical centerburst.

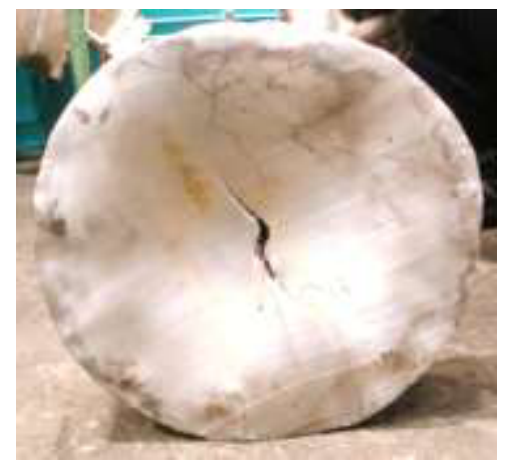

Figure 2. Typical centerburst

Centerbursts in their repulsive/coarse form are chevron like shear fractures that form in the centre of workpiece. In finer form, they may be little more than aggregates of pores along the centreline of the product. They may develop spontaneously or may slowly build up with progressive working. The basic cause of centerbusrting in nonuniform metal flow through dies and associated development of tensile stresses in the center of workpiece. Fracture criterions can be used to predict these Centerbursts during any metal forming operation $[2]$.

\subsection{Fracture Criterion:}

Different fracture criteria are developed for evaluating potential of fracture during particular process. These criterions are generally developed through some workability tests. Fracture criterion extends the workability established in standard conditions to the workability in the deformation process of interest.

Latham-Cockroft Damage Criterion:

It is well reported in a literature that cracking in metal-working processes is associated with tensile stresses; even processes like forging are essentially compressive [2]. However, as both stress and strain can decide the onset of fracture, that criterion should be based on some combination of stress and strain, rather than on either of these quantities [1]. Based on this, there are indications reported in literature that total plastic work done till the fracture is an important factor. If we apply this to tensile test, total plastic work done per unit volume at the fracture point is,

$$
\int_{0}^{\varepsilon_{\mathrm{f}}} \sigma \mathrm{d} \varepsilon
$$

Where, $\sigma$ is current yield stress and $\varepsilon_{\mathrm{f}}$ is fracture strain.

This criterion takes into consideration the yield stress at the onset of fracture and does not takes into consideration the peak stress. Unlike the peak stress, the current yield stress is not influenced by shape of the necked region. The pick stress need to be taken into consideration as it is affected by neck shape. To overcome this limitations, Latham and cockroft has proposed fracture criterion for ductile material. They proposed that fracture occurs in ductile material when the quantity

$$
\int_{0}^{\varepsilon_{\mathrm{f}}} \bar{\sigma}\left(\frac{\sigma^{*}}{\bar{\sigma}}\right) \mathrm{d} \bar{\varepsilon}
$$

reaches a constant value (c) for a given temperature and strain rate, where,

$$
\begin{aligned}
& \bar{\sigma}=\text { equivalent stress, } \\
& \varepsilon_{\mathrm{f}}=\text { fracture strain, } \\
& \bar{\varepsilon}=\text { equivalent strain and }
\end{aligned}
$$

$\left(\frac{\sigma^{*}}{\bar{\sigma}}\right)$ is a non-dimensional stress-concentration factor representing the effect of highest tensile stress- $\sigma^{*}$. The reduced form, given below, is used for calculations, whose expression has the dimensions of work done-

$$
\int_{0}^{\varepsilon_{\mathrm{f}}} \sigma^{*} \mathrm{~d} \varepsilon=\mathrm{C}
$$

This criterion implies that ductile fracture is dependent on both on shear stresses (giving rise to plastic deformation and work hardening) and tensile stresses. Fracture also depends both on the stresses imposed and on the strains developed-neither stress or strain alone[2].

\subsection{FEM application in Metal Forming Simulation}

Recent developments in application of Finite Element Analysis (FEA) to metal forming processes through simulation software's is helping a lot in new product 
development process. Numerical simulation yields a deeper insight into the mechanics of the forming process than that provided by classic calculations and testing techniques. To development of the product, physical tests on a press are necessary; however, with the help of simulation one is in a position to develop the product more quickly and systematically [3].

Transvalor has developed a commercial metal forming simulation software-FORGE-3. The said software is capable doing simulation of hot as well as cold forging process. Dedicated template for Open Die Forging simulation is provided. The said software enables user to carry out stress, strain, temperature analysis. It is also incorporated with built in Latham-Cockroft damage criterion. This FORGE-3 by Transvalor is used for analysis in the present study [4].

\section{Simulations - Design of Experiments (DOE)}

Table 1 gives the details of simulation DOE. As a case for typical open die forging process, process variables under consideration are die combinations, depth of stroke, rotation angle after each pass and forging sequence. The starting billet dimensions are $\varnothing 335(\mathrm{~mm})$ $\times 2000(\mathrm{~mm})$. The starting billet temperature is $30^{\circ} \mathrm{C}$. The input $\varnothing 335$ cross-section is reduced to $\varnothing 315$ in each case. This gives total reduction ratio of $11.58 \%$.

In case no. 1.1 and 1.2, top and bottom dies are flat dies with the die width of $300 \mathrm{~mm}$ and corner radius of $30 \mathrm{~mm}$. After first pass $10 \mathrm{~mm}$ throughout length, except the part hold on manipulator, the job is rotated by $90^{\circ}$. Then for the third pass, job will rotated through $45^{\circ}$ and again through $90^{\circ}$ to make an octagon. The octagon is then converted into round by pressing across the edges. The same process is followed twice for case no. 1.1 i.e. with depth of stroke $10 \mathrm{~mm}$, so as to get final $\varnothing 315 \mathrm{~mm}$.

In case no. 2.1 and 2.2, with the same die combination, instead of making it square-octagon-round, the desired reduction is achieved through $22.5^{\circ}$ rotations per stroke and making the job round locally. Then job is given an axial increment to forge the next part. The same process sequence is followed 4 times for case no. 2.1 i.e. with $5 \mathrm{~mm}$ depth of stroke and 2 times for case no. 2.2 i.e. $10 \mathrm{~mm}$ depth of stroke.

For the case no. 3.1 and 3.2, the similar process sequence is followed with the top $\mathrm{V}$-die instead of flat die.

For the case no. 4.1 and 4.2, the similar process sequence is used with clapper dies in top and bottom. Clapper dies are semi-circular dies with diameter close to operating diameter.

\section{Deformation Model}

Initially, 3D model of the input billet and the dies were prepared using Solid Edge CAD modeling software. Using FORGE software, mesh generation and setting up of input parameters was carried out in a pre-processor stage. The metal flow was evaluated in computation phase. The flow stress equations for deformation, used in FORGE software is shown in Table 2. The flow stress for a chosen material i.e. SS304 as a function of strain, strain rate and temperature was evaluated using Hansel-Spittel equation. The average mesh size used is 15 with remeshing option ON. The FEM mesh of the billet is consisted of 15,811 nodes and 90145 elements. For the individual cases shown in table 2.1, depending upon the no. of passes involved, simulation was completed in 10 to 40 hours.

The friction between the dies and the billet surface depends upon on the amount of reduction, temperature, surface roughness of the dies and die-billet contact time. For present study, is considered coulomb's friction law with friction coefficient of 0.05 . For dissipation of heat generated as a result of cold deformation, heat transfer model considered for present study is with overall heattransfer coefficient of $10000 \mathrm{w} / \mathrm{mm}^{2} \mathrm{~K}$.

Table 1. Simulation DOE

\begin{tabular}{|c|c|c|c|c|c|c|}
\hline \multirow{2}{*}{ Sr. No. } & \multirow{2}{*}{ Iteration } & \multicolumn{2}{|c|}{ Die Combination } & \multirow{2}{*}{$\begin{array}{c}\text { Depth of } \\
\text { Stroke }\end{array}$} & \multirow{2}{*}{ Rotation Angle } & \multirow{2}{*}{$\begin{array}{c}\text { Final } \\
\text { Dimensions }\end{array}$} \\
\hline & & Top Die & Bottom Die & & & \\
\hline \multirow{2}{*}{1} & 1.1 & Flat & Flat & 10 & $90-45-22.5$ & 315 \\
\hline & 1.2 & Flat & Flat & 20 & $90-45-22.5$ & 315 \\
\hline \multirow{2}{*}{2} & 2.1 & Flat & Flat & 5 & 22.5 & 315 \\
\hline & 2.2 & Flat & Flat & 10 & 22.5 & 315 \\
\hline \multirow{2}{*}{3} & 3.1 & Flat & $\mathrm{V}$ & 5 & 22.5 & 315 \\
\hline & 3.2 & Flat & $\mathrm{V}$ & 10 & 22.5 & 315 \\
\hline \multirow{2}{*}{4} & 4.1 & Clapper & Clapper & 5 & 22.5 & 315 \\
\hline & 4.2 & Clapper & Clapper & 10 & 22.5 & 315 \\
\hline
\end{tabular}


Table 2. Rheology and flow stress model used for forging simulation

Flow Stress Model

$$
\sigma_{t}=A_{1} e^{m 1 T} T^{m 9} \varepsilon^{m 2} e^{m 4 / \varepsilon},
$$

$$
(1+\varepsilon)^{m 5 T} e^{m 7 t} \dot{\varepsilon}^{m 3} \dot{\varepsilon}^{m 8 T}
$$

$\sigma_{\mathrm{f}}$ - Flow stress

$\varepsilon$ - Equivalent strain

$\dot{\varepsilon}$ - Strain rate, $\mathrm{A}, \mathrm{m} 1$ to $\mathrm{m} 9$ are constants

Note: Material database in FORGE software has inbuilt values for the constants

\section{Results and Discussion}

In the present study, process parameters affecting the multipass workability are analysed. This includes the analysis of effect of process design on tensile stresses i.e. first Principle stress, hydrostatic pressure, strain penetration, and Latham-Cockroft damage criterion. Since the objective of the exercise is to predict the failure, the values of worst scenario i.e. maximum value of Latham-Cockroft damage criterion is taken and corresponding stress and strain values are taken from same location.

\subsection{Latham-Cockroft Damage criterion}

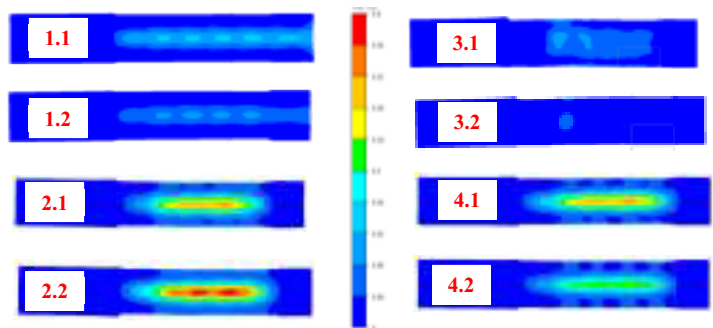

Figure 3. Effect of different processing routes on LathamCockroft Damage criterion

Figure 3 gives the Latham-Cockroft damage criterion profiles for the last pass of all the 4 cases. These values are taken at interior of the workpiece using a cutting plane. The scale with contours blue to red shows the magnitude from 0 to 0.4 . The magnitude goes on increasing from Blue to red colour. In all the cases, material is not likely to have surface damage but has potential for center burst. Since the threshold value for centre burst for a particular material and processing route can be defined only after some shop floor trials, only relative measures can be analysed. Within the analysed options, Flat-V die combination (Case 3.1 and 3.2) has resulted in least damage. It is then followed by flat-flat die combination with $90^{\circ}-45^{\circ}-22.5^{\circ}$ rotation i.e. Squareoctagon-round forging sequence (case no. 1.1 and 1.2). Rest of the two cases has very high chances of center burst.

\subsection{Strain analysis}

Figure 4 gives the strain profiles for the last pass of all the 4 cases. These values are taken at interior of the workpiece using a cutting plane. The scale with contours blue to red shows the magnitude from 0 to 1 . The In all the cases, the strain maps show non-zero values; this means that material is plastically deformed till core. In case of flat-flat die combination with $22.5^{\circ}$ rotations i.e. round-round forging sequence (case no.2.1 and 2.2), the highest strain penetration is observed.

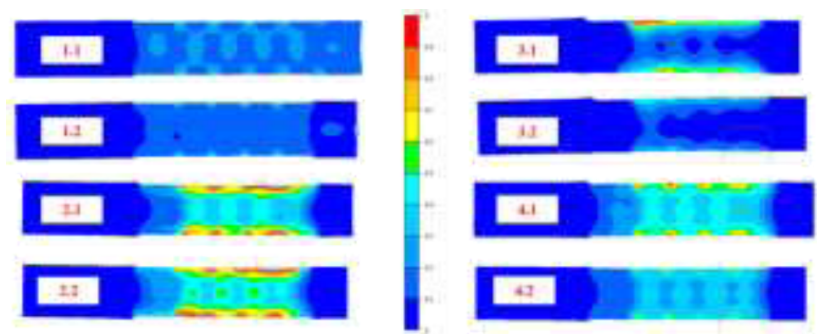

Figure 4. Effect of different process parameters on strain profiles

Similarly, clapper die combination (case 4.1 and 4.2) is also resulted in higher strain penetration. In case of FlatFlat Die combination with $90^{\circ}-45^{\circ}-22.5^{\circ}$ rotation i.e. Square-octagon-round forging sequence (case no. 1.1 and 1.2), minimal strain penetration is observed. In case of Flat-V die combination (case no. 3.1 and 3.2), Strain is concentrated in the periphery and less strain is penetrated in core. This is useful scenario, where product is subsequently subjected to drilling at the core. Since the magnitude of the strain is going to decide the amount of work-hardening and hence the resulting strength enhancement, shop floor trials at different strain levels need to be carried out in order to decide the required strain values. As minimal strain at the core is beneficial in order to control the center burst, process sequence in case 1 and 3 is recommended. It is also observed that for case no. 1, 3, 4, finishing the operation in minimal no. of passes i.e. higher depth of stroke, is turning out beneficial

\subsection{Stress Analysis}
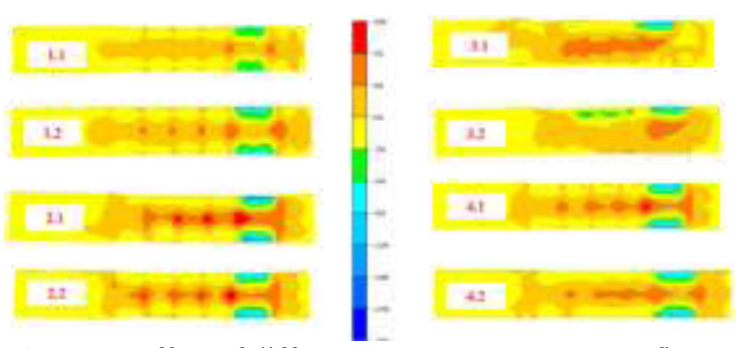

Figure 5. Effect of different process parameters on first principal stress profiles

Figure 5 gives the first principal stress profiles for the last pass of all the 4 cases. These values are taken at 
interior of the workpiece using a cutting plane. The scale with contours blue to red shows the magnitude from 2000Mpa to $1000 \mathrm{Mpa}$. It is clear from the above analysis that, Case no. 1 and 3 are producing lower first principal stress. Being a cold deformation process, the stresses induced in the material keeps on accumulating. To nullify these stresses intermediate annealing is recommended for heavy reductions. However, in the present study, since purpose of the deformation is to enhance the strength using work hardening, intermediate annealing is not recommended.

\subsection{Compiled results and discussion}

Table 3 compiles all the results measured during last pass of each process-as per DOE. These values are taken where the Latham-cockroft criterion is showing maximum value, at a cutting plane at the centre of the width of the billet. Figure 6 to 8 gives graphical representation of effect of process parameters- selected as per DOE-on parameters selected for analysis.

From the analysis, it is clear that the high tensile stress and high strain penetration results in higher Latham-cockroft damage criterions value. This is analogues with the logic and equation of the Lathamcockroft damage criterion.

Table 3. Compiled Results

\begin{tabular}{|c|c|c|c|c|c|c|c|}
\hline $\begin{array}{l}\text { Sr. } \\
\text { No. }\end{array}$ & Iteration & $\begin{array}{c}\text { Equivalent } \\
\text { Strain at } \\
\text { Centre }\end{array}$ & $\begin{array}{c}\text { Latham } \\
\text { Cockroft } \\
\text { damage } \\
\text { Criterion }\end{array}$ & $\begin{array}{c}\text { First } \\
\text { Principal } \\
\text { Stress }\left(\sigma_{1}\right)\end{array}$ & $\begin{array}{c}\text { Second } \\
\text { Principal } \\
\text { Stress }\left(\sigma_{2}\right)\end{array}$ & $\begin{array}{c}\text { Third } \\
\text { Principal } \\
\text { Stress }\left(\sigma_{3}\right)\end{array}$ & $\begin{array}{l}\text { Hydrostatic Stress } \\
\qquad\left(\sigma_{1+} \sigma_{2+} \sigma_{3) / 3}\right.\end{array}$ \\
\hline \multirow{2}{*}{1} & 1.1 & 0.22 & 0.13 & 460 & 110 & -200 & 123.33 \\
\hline & 1.2 & 0.15 & 0.09 & 490 & 130 & -320 & 100 \\
\hline \multirow{2}{*}{2} & 2.1 & 0.37 & 0.31 & 950 & 340 & -40 & 416.67 \\
\hline & 2.2 & 0.42 & 0.39 & 850 & 230 & -450 & 210 \\
\hline \multirow{2}{*}{3} & 3.1 & 0.09 & 0.1 & 495 & 250 & -10 & 245 \\
\hline & 3.2 & 0.05 & 0.04 & 580 & 250 & -40 & 263.33 \\
\hline \multirow{2}{*}{4} & 4.1 & 0.4 & 0.32 & 820 & 230 & -180 & 290 \\
\hline & 4.2 & 0.35 & 0.24 & 690 & 180 & -90 & 260 \\
\hline
\end{tabular}

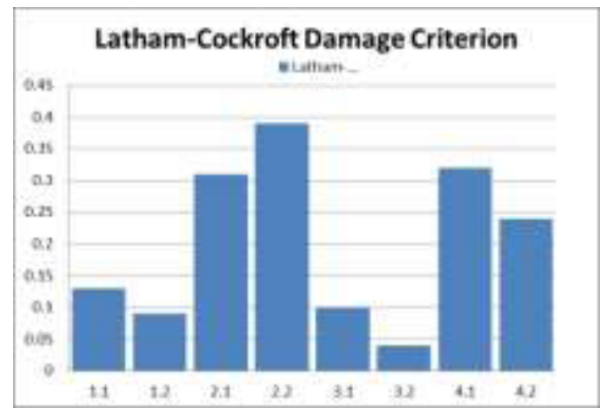

Figure 6. Comparison of Latham-cockroft Damage criteria

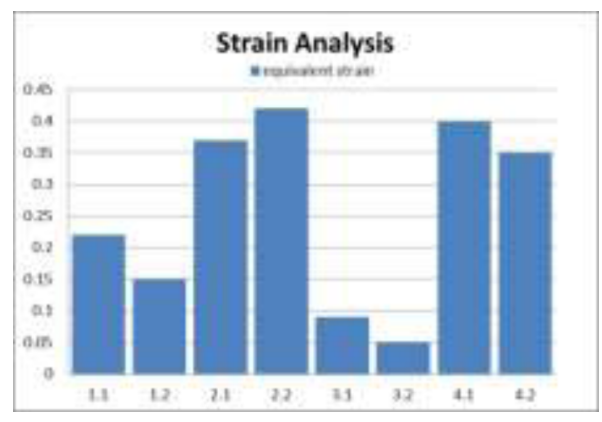

Figure 7. Comparison of strain magnitudes

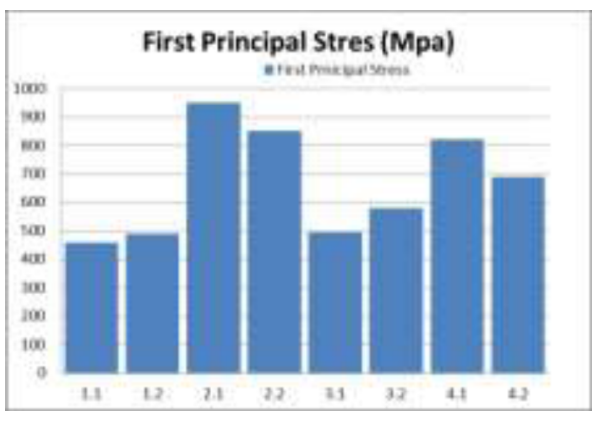

Figure 8. Comparison of first principal stresses

It is clear from the above exercise that for selected application, to avoid centerburst, strain need to be accumulated in the periphery. Also, the process should generate minimum possible tensile stresses at the core. Process which satisfies above conditions is recommended for this application. The threshold value for magnitude of the strain level can be finalised only after shop-floor trials.

The probable reason why case 2 is worse than case 1 may be the strain accumulation due to repetitive strokes at same location. This also results in higher stresses at core, because being a cold deformation; stresses keep on accumulating at the core. Same has happened with in case of clapper dies i.e. case no 4. Due to repetitive strokes, 
accumulated strain and stress levels are high which results in higher damage possibility at centre. In case 3 with Flat-V die combination, geometry of deformation zone helps in getting lesser stresses and strain at core. Also, from analysis of hydrostatic stresses (table 3 ), it is clear that magnitude of highest tensile stresses i.e. first principal stresses is most influencing factor on damage.

With the above analysis, it is clear that FEM tool gives better insights of the mechanics of the deformation process. It is concluded that, among the analysed options, process with Flat and $\mathrm{V}$ die combination i.e. case no. 3 is producing ideal results. It is then followed with case no. 1. Since, in case no. 1.2 and 3.2, with higher depth of stroke, possibility of damage is low compared to 1.1 and 3.1 respectively, these processes are recommended.

\section{References}

1. M.G. Cockroft, D. J. Latham, J. Inst. Met., 96, 33-39 (1968).

2. Dieter: Handbook of workability and process design (2003).

3. Ajit Gaikwad: M.Tech. Thesis: material and process optimization, by simulation, for forging spool body (2011)

4. Web.: www.transvalor.com 